\title{
Challenges in Determining the Substitute Decision Maker: Findings from an Australian Intensive Care Unit
}

\author{
Mendoza JLi*and Burns $\mathrm{CM}^{2}$
}

1John Hunter Hospital, Lookout Road, New Lambton, HMRC 1, Newcastle 2305, NSW Australia

${ }^{2}$ Department of Palliative \& Supportive Services, Faculty of Medicine, Nursing \& Allied Health, Flinders University, Bedford Park 5000, NSW Australia

\begin{abstract}
Background: Little research has been undertaken to explore how Substitute Decision Makers (SDM) are chosen by patients and especially for incompetent adults in an intensive care unit (ICU).

Objective: To determine how substitute decision makers are chosen in ICU.

Method: A retrospective cohort study using a clinical file audit to appraise socio-demographic and qualitative data from the medical record. The data from the medical record was collected by one researcher and analysed using a de-identified file. Ethics approval was sought and granted by the hospital Ethics Committee and the research was deemed to be low risk due to the nature of the retrospective file audit. Setting/Participants Patients admitted to ICU between July 2010 and June $2011(n=1500)$ and died within ICU $(n=236)$. The social demographic features were analysed using descriptive statistics and analysis using SPSS statistical software.

Results: Most patients who died in ICU $(70 \%)$ were aged over 60 years. While most widowed people and some married persons nominated an adult child as next of kin (NOK), 34\% of single people nominated someone other than a family member as next of kin. The audit showed key differences between next of kin and the nominated substitute decision maker. For example, in all age groups, for those nominating a partner as next of kin $(n=124)$ over a third had a different person assume the role of substitute decision maker.

Conclusion: This retrospective study found that one third of patients preferred another trusted advocate to assume the role of substitute decision maker rather than their next of kin. Hence, the NOK of patients admitted to ICU should not be assumed to be their preferred substitute decision-maker. We recommend a community education program to raise awareness for families to begin conversations about preferences for substitute decision makers especially amongst ageing family members.
\end{abstract}

Keywords: Substitute decision maker; End of life care

\section{Introduction}

This research received no specific grant from any funding agency in the public, commercial, or not-for-profit sectors. This data from the medical record was provided by the John Hunter Hospital to Ms Janis Mendoza, a senior clinical social worker and researcher. Analysis undertaken by Dr Catherine Burns used a de-identified file and SPSS software.

\section{Background}

Much has been written regarding the role of a substitute decision maker (SDM) for a non-competent adult in an intensive care unit (ICU) and the importance of effective communication in order to build trusting relationships between the ICU interdisciplinary team and a patient's family including shared decision making to achieve the best outcomes of patient care [1-4]. Clear, consistent communication between the treating team and family and a collaborative approach is the accepted norm [2,5-8]. It is recognised that families at this time face challenges beyond their normal life experience and their decision making capacities can be overwhelmed by the emotional impact of anticipatory grief and the language of ICU which is often alien to them. Hence, the family's ability to truly reflect a patient's wishes is often impaired by the crisis [5,9-11]. Little research has been undertaken to explore how a SDM is chosen by a patient, nor how the SDM is chosen for an incompetent adult in ICU $[8,12,13]$.

In the USA, Lipkin found more than one quarter (28\%) of outpatients chose someone other than the nominated contact person to act as their SDM for medical decision making and one third (33\%) of the married patients did not choose their spouse as their SDM [14]. In Iran, Mirzaei reported that gender and marital status were important factors for outpatients choosing a SDM [15]. Only $51 \%$ of married patients chose their spouse to be SDM. Men tended to choose a brother, whilst the women sampled, preferred to choose a child. Single men preferred their father (36\%) and single girls chose their father in only $5.6 \%$ of cases, preferring other trusted adults $(33.3 \%)$ to be their SDM. Mirzaei reported that substitute decision making in countries of predominately Muslim culture is often impacted by Sharia law where a mother is not recognised as a child's guardian and can only be assigned as guardian with her husband's consent.

In France, Roupie found that of those patients presenting to an emergency department only $57 \%$ of married patients nominated a spouse as their SDM. Azoulay reported a later large survey of French residents exploring attitudes towards substitute decision making if the person were admitted to ICU and unable to make decisions about

*Corresponding author: Mendoza JL, John Hunter Hospital (ICU), Lookout Road New Lambton, NSW 2282, Australia, Tel: 61400997103; E-mail: Janis.Mendoza@ hnehealth.nsw.gov.au

Received April 14, 2016; Accepted June 06, 2016; Published June 13, 2016

Citation: Mendoza JL, Burns CM (2016) Challenges in Determining the Substitute Decision Maker: Findings from an Australian Intensive Care Unit . Adv Practice Nurs 2:115. doi:10.4172/2573-0347.1000115

Copyright: (c) 2016 Mendoza JL, et al. This is an open-access article distributed under the terms of the Creative Commons Attribution License, which permits unrestricted use, distribution, and reproduction in any medium, provided the original author and source are credited. 
their care for themselves [6]. Attitudes appeared to have moved more in line with US/UK and Australian views of patient autonomy and selfdetermination. $21 \%$ said they would choose other than their spouse as SDM and $76 \%$ of respondents preferred their family to share the decision making process [6]. Lesieur in examining organ donation practices, noted that the medical records before admission to one French ICU made no mention of anticipated directives by patients, or of a legally designated trusted person to act a SDM [16].

In Israel, Kuniavsky reported a legal guardian must be appointed by the court as a SDM for all non-life threatening procedures undertaken whilst the patient is in ICU and incompetent to make their own decisions [17]. Most of the legal guardians nominated were children (54.7\%) or spouses (20.3\%). Kuniavsky found that less than half of those surveyed knew the patient's wishes (48.6\%) and the majority preferred a shared decision making process where decisions are made by medical staff after discussion with the family $(65.6 \%)[18,19]$.

In Lebanon, Abou-Mrad reported most substitute decision makers in ICU's were a child of the patient rather than the spouse and felt this was due to the influence of family, cultural and religious traditions in Lebanese society [20]. In India, Sviri also found that the majority of patients admitted to ICU (67\%) had not discussed end of life care preferences with their family members [21]. Berger shared examples of how the treating team could flexibly accommodate substitute decision makers preferences, patient's best interests, and the needs of a grieving family when these diverged from normative standards [9]. Apart from these few studies, there is little reported in the medical literature about how a person comes to such an important decision.

A consensus model of shared decision making between the interdisciplinary team and the family is followed at the ICU where this research was undertaken. Family meetings with an intensive care physician, the bedside nurse and the ICU social worker are held immediately after admission and regularly throughout a patient's stay to inform and update families about the patient's medical condition and prognosis; to determine patient's values and treatment preferences; plan treatment goals; and to resolve conflict amongst family members. Due to rotation of staff, the social worker is usually the consistent team member supporting families in meetings where medical updates are provided and goals of care, including end of life care are planned.

\section{Objective}

The aim of this report is to examine differences between nominated next of kin and substitute decision maker and to explore and discuss how patients coming to ICU have determined their choice of substitute decision maker.

\section{Method}

In Australia there are 5.5 ICU beds per 100,000 population. The ICU studied is in a major regional tertiary level, university affiliated hospital. The ICU treats adult and children, medical, surgical, neurological, cardiac and trauma patients and has a bed occupancy of $89 \%$. The ICU operates as a closed unit where the ICU physician acts as gatekeeper to patient admissions. The hospital provides tertiary level care to an area of 131,000 square kilometres, which is similar to the size of England, UK or Louisiana, USA. This clinical audit gathered descriptive demographic data of deaths in ICU over a 12 month period. The study sought to examine social demographic and clinical characteristics of the population who died while receiving care.

Study Population: Patients who were admitted to the ICU between
July 2010 and June 2011 were eligible for inclusion in the study. $(\mathrm{n}=1500)$.

Inclusion Criteria: Patients who died during their ICU admission $(n=236)$.

Data Collection: retrospective cohort study examining clinical and socio-demographic data in the medical record. Quantitative data collected included age, marital status, country of birth, religion, employment status, place of residence, next of kin and clinical features of the population (diagnosis, reason for admission, pathway into ICU, length of stay and cause of death).

Qualitative data was obtained using documentation from the patient medical record to retrieve information which related to family conflict at the time of palliation in regard to the role of the SDM. All data was collected by one researcher. The researcher identified when there was a discrepancy between nominated NOK entered on the demographic data sheet of the patient's medical record and the SDM nominated by the family and subsequently recorded in the patient's medical record by either the social worker or bedside nurse.

Data analysis: The social demographic and clinical features were analysed using descriptive statistics and SPSS software was used to statistical analysis. The qualitative data was analysed using thematic analysis. The social worker and nursing staff had documented in the patient's medical record when conflict over the role of SDM was observed or reported by family members to staff. The researcher used this data for thematic analysis.

\section{Findings}

The majority of those who died in ICU were aged over 60 years $(72.5 \%)$ and $22.8 \%$ were aged over 80 years (Table 1 ). Half of patients who died (51.3\%) were not married. Amongst the deceased who were married, $4.7 \%$ lived in aged care facilities, and $16 \%$ lived with other family members. Over a quarter (28\%) of patients lived alone (Table 2).

This study found that those who had died in ICU are likely to be single men, or widowed women and their preferred SDM often diverged from the recognised guardianship hierarchy [13].

Most widowed people nominated an adult child as NOK, but $8 \%$ preferred other relatives or friends. Married persons sometimes nominated an adult child as NOK and $34 \%$ of single people nominated someone other than family as NOK. While half of patients nominated their partner as NOK, this dropped to $37 \%$ when the record identified the SDM. The audit undertaken showed key differences between NOK and the SDM. In all age groups, for those nominating a partner as NOK $(n=124)$, over a third had a different person assume the role of SDM. Among older patients, $(>60 \mathrm{yrs})$ it was the adult child who most often assumed this role (Table 3 ).

Only two patients had written advance care directives. Eleven patients had informed their families of their preferences and the families of the remaining 223 patients relied on their perceptions of the patient's values, rather than any clear knowledge of their expressed wishes about end of life care.

A qualitative analysis of patient files found that those chosen by a patient to be their SDM were often overruled by the family during end of life discussions. The process of choosing a SDM is often idiosyncratic and uniquely personal. Those chosen are usually someone that the patient knows well and is trusted to reflect their values and wishes. There were many examples of where the NOK differed from 
Citation: Mendoza JL, Burns CM (2016) Challenges in Determining the Substitute Decision Maker: Findings from an Australian Intensive Care Unit . Adv Practice Nurs 2:115. doi:10.4172/2573-0347.1000115

Page 3 of 3

\begin{tabular}{|c|c|}
\hline Characteristics & $\mathrm{n}=236 \%$ \\
\hline Sex & \\
Male & 57.6 \\
Female & 42.4 \\
\hline Age & \\
$<50$ & 16.5 \\
$50-59$ & 11.0 \\
$60-69$ & 22.2 \\
$70-79$ & 27.5 \\
$>80$ & 22.8 \\
\hline Marital status & 14.9 \\
Single & 48.7 \\
Married & 14.8 \\
Separated/divorced & 21.6 \\
Widowed & \\
\hline Country of birth & 86.0 \\
Australia & 14.0 \\
Other & \\
\hline
\end{tabular}

Table 1: Socio-demographic of the Population who died in JHH_ICU.

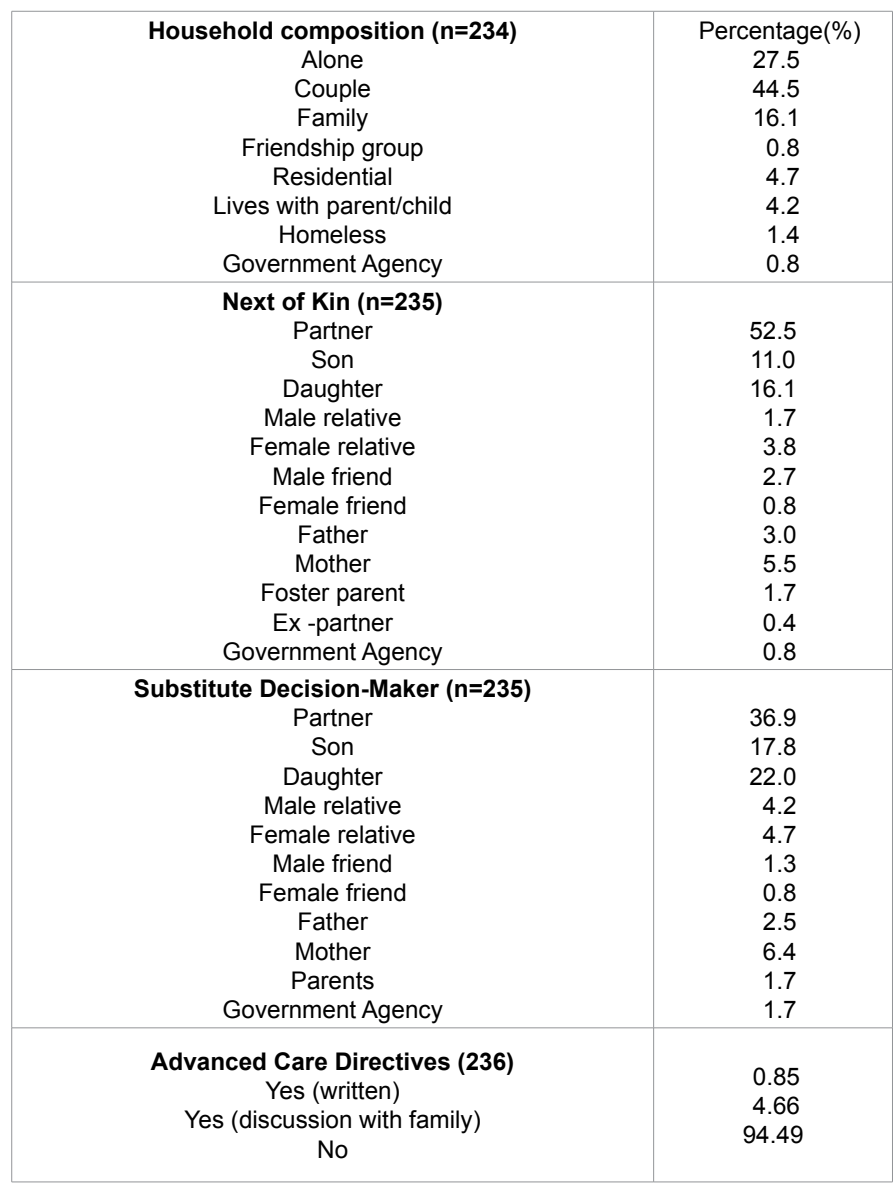

Table 2: Household composition, next of kin and Substitute Decision Maker.

the SDM. These figures reflect the high potential for family conflict which can contribute to lack of consensus in family meetings around end of life care decision making. The conflict resolution and mediation skills brought to the team by a social worker can enable potentially problematic family dynamics to be addressed in a timely manner.

\section{Limitations}

There are limitations in the findings of this study. The data is a clinical audit obtained retrospectively from the medical record files of patients at a single centre. The study was designed to describe the

\begin{tabular}{|c|r|r|r|r|r|r|r|r|r|r|r|}
\hline \multirow{2}{*}{ Characteristics } & \multicolumn{2}{|c|}{$<60$ years } & \multicolumn{2}{|c|}{$\begin{array}{c}60-70 \\
\text { years }\end{array}$} & \multicolumn{2}{c|}{$\begin{array}{c}71-80 \\
\text { years }\end{array}$} & \multicolumn{2}{c|}{$80+$ years } & \multicolumn{2}{|c|}{ Total } \\
\cline { 2 - 13 } & NOK & SDM & NOK & SDM & NOK & SDM & NOK & SDM & NOK & SDM \\
\hline Partner & 24 & 17 & 38 & 36 & 36 & 26 & 26 & 8 & 124 & 87 \\
\hline Adult child & 8 & 6 & 9 & 13 & 21 & 31 & 26 & 43 & 64 & 93 \\
\hline $\begin{array}{c}\text { Relatives/ } \\
\text { friends }\end{array}$ & 7 & 13 & 5 & 3 & 8 & 7 & 2 & 3 & 22 & 26 \\
\hline Parents & 26 & 29 & 0 & 0 & 0 & 0 & 0 & 0 & 26 & 29 \\
\hline Total & 65 & 65 & 52 & 52 & 65 & 65 & 54 & 54 & 236 & 235 \\
\hline
\end{tabular}

Table 3: Nominated Next of Kin $(N O K) \times$ Substitute Decision Maker $(\mathrm{SDM}) \times$ Age $P$ value for $\mathrm{NoK}=<0.001$ and for $\mathrm{SDM}=<0.001$.

epidemiological characteristics of patients deceased in an Australian ICU over a one year period. It offers an insight and platform for a more sophisticated investigation.

\section{Discussion}

Our findings reflect previous overseas studies that report that $30 \%$ of patients prefer another trusted advocate rather than their spouse to be nominated as the SDM [6,14-17]. Hence, physicians and nursing staff should be mindful of this when they raise end of life care issues with families and seek broader family consensus.

The social worker in the ICU where this research was undertaken routinely assesses family relationships to establish the reliability of the SDM and to mediate between family members in the event of disagreement with the choice of SDM in order to gain cooperation and consensus with the ICU team. In this study the social worker found families often lacked understanding of the role of SDM, whom they perceived to be the most important person in the family, rather than having regard for, or being able to truly reflect the patient's values and wishes for end of life care, especially given that only $5 \%$ of families were aware of the patient's wishes [12]. Blended families are rapidly becoming the norm and new partners and adult children of first marriages can create challenging dynamics. Adult children often overruled a current partner, claiming the longevity of their relationship even when they had not maintained close contact with the patient.

Single people who had nominated a friend as NOK were often overruled or bullied by family members to relinquish the role. The task of the SDM was made more challenging by the fact that most patients had not considered preferences for end of life care prior to their ICU admission and had not shared their feelings or wishes with close family members. This was evident even for those patients who suffered chronic illness. This presents many challenges for the ICU team where patient's wishes are often pondered by family members rather than known. Families are encouraged to consider and reflect upon the patient's beliefs and values and to be their voice in this difficult situation, in order to ensure the patient's wishes are honoured. However, it is often difficult for a family member to separate their own needs and wishes from what those of the patient might be [12]. Our socio-demographic profile confirms a high proportion of people dying in ICU are elderly. One patient, an 87 year old man had been told by his cardiac physician that he would be likely to die within 12 months. However following a crisis admission from a ward due to an emergency response call for respiratory distress, his family said they had not had a conversation around his end of life wishes, demanded full active treatment and refused to consider treatment limitations. Advance directives may reconcile people's wishes at the end of their own lives with their reticence to make decisions regarding others [18]. Of the two patients who did have an advanced care directive, one was brought to 
Citation: Mendoza JL, Burns CM (2016) Challenges in Determining the Substitute Decision Maker: Findings from an Australian Intensive Care Unit . Adv Practice Nurs 2:115. doi:10.4172/2573-0347.1000115

the attention of staff 2 days after their admission. The family had not been aware of the existence of the directive and did not understand its importance.

The counselling provided by the social worker to families and their ongoing discussions with the bedside nurse about the nature of their illness may provide opportunities to help to clarify the patient and family's perception of their health and functional ability and their evolving values surrounding future quality of life particularly after an ICU admission, and the impact of living with significant disability and dependency. This may encourage discussion of end of life care preferences and the preparation of advanced care directives.

The homogeneity of this study, unlike other large metropolitan Australian cities where $25 \%$ of the population is overseas born, restricts our findings $(86 \%$ of deceased patients in this study were Australian born). Nonetheless, for Australian physicians, the differing cultural practices and milieu are important considerations for good patient care. Whilst respect for a patient's autonomy is the guiding principle impacting a substitute decision maker's role, the team must remain mindful of providing holistic care inclusive of a family's cultural needs. Hence, the expectation amongst overseas born patients for a paternalistic approach from physicians which remains common for those patients from some European, Asian and Middle Eastern backgrounds can create communication challenges for the ICU team committed to respect for patient autonomy.

The government in the state where this research was undertaken has recently begun a media campaign addressing the importance of planning for the end of life and recommending that people consider making a will; nominate an enduring guardian and talk to loved ones about their wishes for end of life care. It will be interesting to assess the impact of this campaign upon people's reticence to discuss and share their views around these issues.

\section{Conclusion}

This study highlights the need for families to begin conversations about preferences for their end of life care. Especially given that an ICU environment is not an ideal setting for end of life care for elderly patients suffering chronic conditions. The question of the most appropriate SDM also needs to be addressed by families long before a hospital admission. This may require innovative health promotion strategies in order to facilitate greater awareness of the value of conversations around end of life care wishes. The experience of those patients who survive their ICU admission may provide motivation to facilitate these conversations in order that the patient is more prepared for a future event, particularly for older patients and those suffering a chronic or life limiting illness. This study offers an insight and platform for a more sophisticated investigation of the role of the SDM.

We need to actively raise, through public discussion, the importance of clarifying and sharing with families and treating physicians EOL care preferences. We should also as a society be deciding what we can afford to offer. General frailty has become a leading cause of death and physicians should have courage to refuse admission to ICU for patients who are perceived not to benefit, but rather support and facilitate the dying process at ward level or ideally in the home environment with the support of palliative care teams.

\section{References}

1. Azoulay E, Sprung CL (2004) Family-physician interactions in the intensive care unit. Crit Care Med 32: 2323-2328.
2. Bomba PA, Morrissey MB, Leven DC (2011) Key role of social work in effective communication and conflict resolution process: Medical Orders for LifeSustaining Treatment (MOLST) Program in New York and shared medical decision making at the end of life. J Soc Work End Life Palliat Care 7: 56-82.

3. Curtis JR (2004) Communicating about end-of-life care with patients and families in the intensive care unit. Crit Care Clin 20: 363-380.

4. Prendergast TJ, Puntillo KA (2002) Withdrawal of life support: intensive caring at the end of life. JAMA 288: 2732-2740.

5. Ahrens T, Yancey V, Kollef M (2003) Improving family communications at the end of life: implications for length of stay in the intensive care unit and resource use. Am J Crit Care 12: 317-323.

6. Azoulay E, Pochard F, Chevret S, Adrie C, Bollaert PE, et al. (2003) Opinions about surrogate designation: a population survey in France. Crit Care Med 31: $1711-1714$.

7. Curtis JR, Vincent JL (2010) Ethics and end-of-life care for adults in the intensive care unit. Lancet 376: 1347-1353.

8. Lautrette A, Peigne V, Watts J, Souweine B, Azoulay E (2008) Surrogate decision makers for incompetent ICU patients: a European perspective. Curr Opin Crit Care 14: 714-719.

9. Berger JT, DeRenzo EG, Schwartz J (2008) Surrogate decision making reconciling ethical theory and clinical practice. Annals of internal medicine 149 $48-53$

10. Siddiqui S, Sheikh F, Kamal R (2011) "What families want - an assessment of family expectations in the ICU”. Int Arch Med 4: 21

11. Arnold RM, Kellum J (2003) Moral justifications for surrogate decision making in the intensive care unit: implications and limitations. Crit Care Med 31: S347353.

12. Mendoza JL, Burns CM (2015) 'Who Will Talk for Me?' Next of Kin is not necessarily the preferred substitute decision maker: Findings from an Australian intensive care unit. Palliat Med 29: 391-392.

13. (1987) Guardianship Act (NSW) 257.

14. Lipkin KM (2006) Brief report: identifying a proxy for health care as part of routine medical inquiry. J Gen Intern Med 21: 1188-1191.

15. Mirzaei K, Milanifar A, Asghari F (2011) Patients' perspectives of the substitute decision maker: who makes better decisions? J Med Ethics 37: 523-525.

16. Lesieur O, Mamzer MF, Leloup M, Gonzalez F, Herbland A, et al. (2013) Eligibility of patients withheld or withdrawn from life-sustaining treatment to organ donation after circulatory arrest death: epidemiological feasibility study in a French Intensive Care Unit. Ann Intensive Care 3: 36

17. Kuniavsky M, Ganz FD, Linton DM, Sviri, S (2012) The legal guardians' dilemma: Decision making associated with invasive non-life-saving procedures. Isr J Health Policy Res 1:36.

18. Sviri S, Garb Y, Stav I, Rubinow A, Linton DM, et al. (2009) Contradictions in end-of-life decisions for self and other, expressed by relatives of chronically ventilated patients. J Crit Care 24: 293-301.

19. Roupie E, Santin A, Boulme R, Wartel JS, Lepage E et al. (2000) Patients' preferences concerning medical information and surrogacy: results of a prospective study in a French emergency department. Intensive Care Med 26 : $52-56$.

20. Abou-Mrad F, Mourad C, Najem C (2012) Depressive symptoms among surrogate decision makers in Lebanese ICUs. Funct Neurol 27: 95-99.

21. Emanuel EJ, Emanuel LL (1998) The promise of a good death. Lancet 351 Suppl 2: SII21-29. 